\title{
Estimation of Steel Consumption and Obsolete Scrap Generation in Japan and Asian Countries in the Future
}

\author{
Yuma IGARASHI, ${ }^{1)}$ Elijah KAKIUCHI, ${ }^{2)}$ Ichiro DAIGO, ${ }^{3)}$ Yasunari MATSUNO ${ }^{3)}$ and Yoshihiro ADACHI \\ 1) Formerly Graduate Student, Department of Materials Engineering, Graduate School of Engineering, University of Tokyo. \\ Now at JFE Steel Corporation. 2) Graduate Student, Department of Materials Engineering, Graduate School of \\ Engineering, University of Tokyo. $\quad 3$ ) Department of Materials Engineering, Graduate School of Engineering, University
} of Tokyo.

(Received on January 8, 2008; accepted on February 15, 2008; originally published in Tetsu-to-Hagané, Vol. 93, 2007, No. 12, pp. 782-791)

\begin{abstract}
The present flows of steel scraps in Japan, China, South Korea and Taiwan are described, and a dynamic model that analyzes future scrap flows was developed. To estimate obsolete scrap recovery, a population balance model (PBM) was used for Japan, South Korea and Taiwan. The PBM dynamically estimated the amount of discarded steel by taking into account steel input into a society by end use and the lifetime distributions of each end use. For China, obsolete scrap recovery was estimated using a leaching model, which used the steel stock and the recovery ratio of obsolete scraps. Three different methods were applied to forecast future steel input for each country. The first method applied the assumption that steel demand in the future remains at the present level. The second method applied a logistic curve to estimate future steel stock. The third method applied regression equations to future steel input by end use. GDP and population were used as variables. Finally, the steel input forecasts produced by each method were substituted into the obsolete scrap recovery estimation model. The logistic curve method estimated that in 2030 obsolete scrap recovery would be 29 million tons in Japan, 83 million tons in China, 20 million tons in South Korea, and 3.7 million tons in Taiwan.
\end{abstract}

KEY WORDS: China; Japan; South Korea; Steel scrap; Taiwan.

\section{Introduction}

World crude steel production reached 1.1 billion tons in 2005. Total production in Japan, China, Korea and Taiwan was 530 million tons, which accounted for approximately $47 \%$ of the world production. Recently, China, Korea and Taiwan have been increasing their crude steel production and have been importing steel scraps to meet production needs. ${ }^{1)}$ Therefore, a gap between the demand for steel scraps and the actual amount of recovery has developed in these countries, in which steel scrap supply is inadequate. In contrast, crude steel production in Japan exceeded 100 million tons in 1972, and has remained above that level due to the continuously increasing steel production plans. The amount of available steel stock in Japan has increased as well. The rate of steel recycling from post-consumer products has increased as a result of the promulgation of the Basic Law for Establishing a Recycling-based Society. The major markets for Japan steel scraps exports, which began in 1996, are China, Korea and Taiwan. In 2004, exports to these countries were 2.79 million tons to China, 2.66 million tons to Korea, and 0.93 million tons to Taiwan. Over $90 \%$ of the total amount of exported steel scraps from Japan (6.81 million tons) was exported to these three countries.
In a previous study, the authors estimated future steel scraps generation in Japan by taking into account past steel input into society by end use using a population balance model (PBM). ${ }^{2)}$ By assuming present steel demand levels, scrap generation in Japan in 2015 was estimated to increase to approximately 45 million tons. Moreover, the quality of exported scraps was expected to affect the quality of domestic scraps. Therefore, trends in scrap exports are important for planning the effective usage of steel scraps.

Predicting the future demand of steel in Asian countries, such as China, where the economy and the demand for steel are growing very rapidly is particularly challenging. The material flow must be analyzed to determine the balance of supply and demand of steel. Steel demand in each country is affected by factors such as population growth, economic growth, and demand trends for finished products (e.g. automobiles, buildings, home electric appliances). Although several studies have attempted to forecast future steel demand, ${ }^{3,4)}$ studies have not been completed that predict material flow, including scraps generation, with the exception of a study on lead by Elshkaki et al. ${ }^{5}$ )

The current study forecasts steel demand in Japan, China, Korea, and Taiwan and analyzes the future material flow of steel scraps using the demand forecast. 


\section{Development of Material Flow Model}

\subsection{Estimation of Steel Input}

The residence time of steel in society and the recovery ratio of obsolete scraps differ among the end uses of steel. ${ }^{2)}$ Therefore, steel input in Japan before 2004 was estimated by each end use.

Steel consumption was estimated by adding steel imports to and subtracting steel exports from steel production. Then, steel input into society was estimated by subtracting process yield scrap shipments and indirect exports from steel consumption and adding indirect imports. Indirect imports and exports are the steel imported and exported, respectively, by finished steel product industries.

Steel input by end use in Japan from 1945 to 2004 was estimated in the following manner. Steel consumption by end use from 1971 to 2000 was obtained by conducting an interview survey. ${ }^{6)}$ Process yield scrap shipments from 1980 to 2000 were obtained from literature. ${ }^{7)}$ Estimates of process yield scrap shipments from 1971 to 1979 assumed that the generation rates of process yield scraps for each end use were the same as those in 1980. Indirect imports and exports from 1971 to 2000 were also obtained from the interview survey. ${ }^{6}$ These data were used to estimate steel input by end use from 1971 to 2000 . Steel input by end use from 1945 to 1970 was estimated by multiplying crude steel production for each year ${ }^{8)}$ by the steel input by end use in 1971, and then dividing the product by crude steel production in 1971. Steel input by end use from 2001 to 2004 was estimated by multiplying the award volume of steel by end use each year ${ }^{9)}$ by steel input by end use in 2000, and then dividing the product by the award volume of steel by end use in 2000.

For China, the steel input by end use from 1949 to 2004 was estimated in the following manner. Steel production, imports and exports from 1949 to 2002 were based on a private communication. ${ }^{6}$ ) Steel consumption by end use from 1949 to 2002 was estimated by multiplying steel consumption by the rate of steel shipments according to end use, which was obtained from literature ${ }^{10)}$ for 1983 to 2000. The rates for the years that were not available in literature ${ }^{10)}$ were estimated using linear interpolation approximation. The rates for years prior to 1983 were assumed to be the same as those for 1983. The rates for 2001 and 2002 were obtained by conducting an interview survey. ${ }^{6}$ Estimates of process yield scrap shipments from 1949 to 2002 assumed that the rates of process yield scrap shipments for each end use were the same as those in Japan in 1994. Indirect imports and exports of steel for "construction" and "containers" in Japan were extremely small. Therefore, indirect trade in steel for "automobiles", "machinery," and "other products" were considered for China. The rates of indirect imports and exports of steel for "automobile" production from 1955 to 2002 were estimated using the number of automobiles produced, imported, and exported. ${ }^{11)}$ The rates for years prior to 1955 were assumed to be the same as those for 1955. The rates of indirect imports and exports of electric and electronic machinery from 1991 to 2003 were estimated from the value of production, imports, and exports of electronics. ${ }^{12,13)}$ The rates for years prior to 1991 were assumed to be the same as those for 1991. The rates of indirect imports and exports of steel for industrial machinery from 1990 to 2003 were estimated in the same manner as electric and electronic machinery, from the value of production, imports, and exports of industrial machinery. ${ }^{11,14)}$ The rates in years prior to 1990 were assumed to be the same as those for 1990. Electric and electronic machinery and industrial machinery were defined as "machinery". The steel used for "other products" is used in subsequent processes, and a large part of subsequent processes is used for the construction of "machinery". ${ }^{15)}$ Therefore, the rates of indirect imports and exports of steel for "other products" were estimated to be the same as those for "machinery". Indirect imports and exports were estimated by subtracting process yield scrap shipments from steel consumption, and then multiplying by the rates of indirect imports and exports, which were estimated in the previous manner. From these data, steel input by end use from 1949 to 2002 was estimated. Steel input by end use in 2003 and 2004 was estimated by multiplying crude steel production for each year $^{16)}$ by the steel input according to end use in 2002, and then dividing by crude steel production in 2002 .

For South Korea, steel input by end use from 1930 to 2003 was estimated in the following manner. Steel consumption, indirect imports, and exports from 1930 to 2003 were obtained from literature. ${ }^{17)}$ Data for the years that were not available in literature ${ }^{17)}$ were estimated by assuming that the rate of change remained constant over the period of missing data. Steel consumption by end use from 1949 to 2002 was estimated by multiplying steel consumption by the rates of steel shipments according to end use, which were obtained from literature ${ }^{10)}$ for 1988 to 2000. The rates for the years that were not available in literature ${ }^{10)}$ were estimated by linear interpolation approximation. The rates for years prior to 1988 were assumed to be the same as those in 1988. Similarly, the rates for years after 2000 were assumed to be the same as those in 2000. Process yield scrap shipments from 1930 to 2002 were estimated by assuming that the rates of process yield scrap shipments for each end use were the same as those in Japan in 1994. Indirect imports and exports of steel for "construction" and "containers" in Japan were extremely small. Therefore indirect steel trade for "automobiles", "machinery", and "other products" were considered for South Korea. The rates of indirect imports and exports of steel for "automobiles" from 1965 to 2003 were estimated from the number of automobiles produced, imported, and exported. ${ }^{18)}$ The numbers of imports and exports for the years that could not be obtained from statistics were estimated by assuming that they had the same rates of change as the volume of production. The rates of indirect trades for years prior to 1965 were assumed to be the same as that in 1965. Indirect imports and exports of steel for "automobiles" from 1930 to 2003 were estimated by subtracting process yield scrap shipments from steel consumption, and then multiplying by the estimated rates of indirect imports and exports of automobiles. Indirect imports and exports of steel for "machinery" and "other products" from 1930 to 2003 were obtained by subtracting indirect imports and exports of steel for "automobiles" from the total amount of indirect imports and exports of steel. Most steel for "other products" is used for subsequent processes, e.g. production of springs, metal molds, 
screws, and a large part of steel for the subsequent processes is used in "machinery". ${ }^{15)}$ Therefore, the rates of indirect imports and exports of steel for "other products" were assumed to be the same as those for "machinery". Indirect imports and exports of steel used for "machinery" and "other products" were estimated, respectively, by dividing the total indirect imports and exports of steel used for "machinery" and "other products" by "the amount obtained by subtracting process yield scrap shipments from steel consumption for machinery" and "the amount obtained by subtracting process yield scrap shipments from steel consumption for other products". Steel input by end use from 1930 to 2003 was estimated based on these data.

For Taiwan, steel input by end use from 1949 to 2003 was estimated in the following manner. Steel consumption from 1971 to 2003 was obtained from literature. ${ }^{16)}$ Steel consumption by end use from 1949 to 2003 was estimated by multiplying steel consumption by the 1983 to 2000 rates of steel shipments according to end use, which were obtained from literature. ${ }^{10)}$ The rates for the years that were not available in literature ${ }^{10)}$ were estimated by linear interpolation approximation. The rates for years prior to 1983 were assumed to be the same as that in 1983. Similarly, the rates for years after 2000 were assumed to be the same as that in 2000. Process yield scrap shipments from 1949 to 2003 were estimated by assuming that the rates of process yield scrap shipments for each end use were the same as those in Japan in 1994. Indirect imports and exports of steel for "construction" and "containers" in Japan were extremely small. Therefore, indirect steel trade of steel for "automobiles", "machinery" and "other products" was considered for Taiwan. The rates of indirect imports and exports of steel for "automobiles" from 1979 to 2003 were estimated from the number of automobiles produced and exported, ${ }^{19)}$ and the proportions of newly registered automobiles that were imported. ${ }^{20,21)}$ The numbers of exports for the years that could not be obtained from statistics were estimated by assuming that they had the same rates of change as the volume of production. The rates of indirect trade for years prior to 1979 were assumed to be the same as that in 1979.

The values of production, imports, and exports of "machinery" from 1997 to 2002 were obtained from literature. $^{22)}$ The total values of imports and exports from 1976 to 1997 were obtained from literature. ${ }^{23)}$ The values of imports and exports of "machinery" from 1976 to 1996 were estimated by assuming that the ratios of "machinery" trade to the total value of trade were the same as that in 1997. The rates of indirect trade for years prior to 1976 were assumed to be the same as that in 1976. In this manner, the rates of indirect steel trade for "machinery" were estimated. Steel categorized as "other products" was mainly used for subsequent processes, e.g. production of springs, metal molds, and screws, and most of these parts were used to build "machinery". 15) Therefore, the rates of indirect imports and exports of steel for "other products" were estimated to be the same as those for "machinery". Indirect imports and exports of steel were estimated by subtracting process yield scrap shipments from steel consumption, and then multiplying by the rates of indirect imports and exports, which were estimated in the above manner. The steel input by end use from 1949 to 2003 was estimated from these data.

\subsection{Estimation of Scrap Recovery}

Steel scraps can be divided broadly into three categories: in-house scraps, which are generated during steel production; process yield scraps, which are generated during the fabrication of finished products; and, obsolete scraps, which are generated through the reclamation of discarded finished products. Mostly, statistics compiled in many countries do not report data for scraps classified in the above categories. Therefore, the amounts of in-house scrap generation, process yield scrap shipments, and obsolete scrap recovery need to be estimated. The availability of statistics on scrap recovery varies in Japan, China, South Korea and Taiwan, requiring different methods to be adopted for each country. Process yield scrap shipments were estimated as described in Sec. 2.1. For Japan, South Korea, and Taiwan, in-house scrap generation and obsolete scrap recovery were estimated in the following manner. Statistics on in-house scrap generation was available for Japan, South Korea, and Taiwan. Obsolete scrap recovery was estimated by subtracting process yield scraps from purchased scraps, which were based on available statistics. In this manner, scrap recovery was estimated according to generation sources in the three countries.

In-house scrap generation and obsolete scrap recovery in China were estimated in a different manner. A correlation exists between the rate of in-house scrap generation and the continuous casting rate. ${ }^{24)}$ Therefore, the rate of in-house scrap generation in China from 1993 to 2004 was estimated by deriving a regression equation between the two rates. First, a correlation equation (Eq. (1)) was derived using the least square method between the rate of in-house scrap generation and the continuous casting rate in Japan during the period from 1976 to 2004.

$$
y=0.1097 x^{2}-0.2289 x+0.2171
$$

where $y$ is the rate of in-house scrap generation and $x$ is the continuous casting rate. The determination coefficient was 0.9010. The 1976 data were used because the 1993 continuous casting rate in China was approximately equal to the rate in Japan in 1976, which was 35\%. Next, the modification coefficients for each year were derived. The published generation rates for in-house scraps in China were $18.6 \%$ in 1995 , and $6.9 \%$ in 2003. ${ }^{1)}$ When the continuous casting rates were substituted into Eq. (1), the rates of in-house scrap generation were $13.5 \%$ in 1995 , and $9.9 \%$ in 2003 . Therefore, the 1995 modification coefficient of 1.377 was obtained by dividing 18.6 by 13.5 , and the 2003 modification coefficient of 0.6966 was obtained by dividing 6.9 by 9.9. The modification coefficients for the years prior to 1995, from 1996 to 2002, and after 2003 were derived by assuming that the rate of change remained constant over the period. In-house scrap generation, process yield scrap shipments, estimated as described in Sec. 2.1, and scrap imports were subtracted from the amount of scraps used in steel production to estimate obsolete scrap recovery. In this manner, in-house scrap generation, process yield scrap shipments, and obsolete scrap recovery were estimated for Japan, China, South Korea, and Taiwan. 


\subsection{Development of the Obsolete Scrap Recovery Esti- mation Model}

Two types of obsolete scrap recovery estimation models were applied in the current study. The first is a population balance model $(\mathrm{PBM})^{25)}$ and the other is a leaching model. ${ }^{26)}$ Equation (2) describes the PBM estimate of obsolete scrap recovery, $O_{\mathrm{PBM}}(t)$, for each end use in a certain year $t$ using input from previous years $I(t-a)$ and by setting lifetime distributions, $g(a)$, and recovery rates, $C_{\mathrm{PBM}}$, for each end use. Here, $a$ is the age of a product, and $a_{\max }$ is the maximum product lifetime. The leaching model estimated obsolete scraps recovery $O_{\text {Leaching }}(t)$ from steel stock $S(t)$ and the recovery rate against the stock $C_{\text {Leaching }}$ as described in Eq. (3).

$$
\begin{array}{r}
O_{\mathrm{PBM}}(t)=C_{\mathrm{PBM}} \times \sum_{a=0}^{a_{\max }} I(t-a) g(a) \\
O_{\text {Leaching }}(t)=C_{\text {Leaching }} \times S(t) \ldots \ldots \ldots
\end{array}
$$

Parameters used in the PBM for Japan, South Korea and Taiwan are shown in Table $\mathbf{1 .}$

The parameters used for Japan were set in the following manner. The lifetime distribution of steel for "buildings" was obtained from a previous study on the average lifespan of steel-frame offices by Komatsu et al. ${ }^{27)}$ The simple average lifespan of steel for "infrastructure" was obtained from literature ${ }^{28)}$ and the functional form was assumed to be the same as that for "buildings". The lifetime distribution of steel for "machinery" was obtained from the previous study by Toi et al. ${ }^{29)}$ The lifetime distribution of steel for "passenger cars" was obtained from the previous study by Daigo et al. ${ }^{30)}$ The lifetime distribution of steel for "trucks and buses" was obtained from the previous study by Fujimaki. ${ }^{31)}$ The lifetime distribution of steel for "containers" was obtained from the previous study by Daigo et al. ${ }^{2)}$ Information provided by a personal interview ${ }^{6}$ revealed that steel categorized as "other products" was mainly used for subsequent processes, e.g. production of springs, metal molds, and screws. Most of these parts could be assumed to be used to build "machinery". ${ }^{15)}$ Therefore, the lifetime distribution of steel for "other products" was assumed to be the same as the steel required for "machinery". A Weibull

Table 1. Lifetime distribution functions for each end use in

\begin{tabular}{|c|c|c|c|c|}
\hline & Average lifetime [year] & Recovery rate & Reference \\
\hline \multirow{7}{*}{ 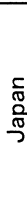 } & Buildings & 28.9 & $70 \%$ & 27 \\
\hline & Infrastructure & 34.5 & $30 \%$ & 28 \\
\hline & Machinery & 12.1 & $80 \%$ & 25,29 \\
\hline & Passenger cars & 11.9 & $85 \%$ & $30,32,33$ \\
\hline & Trucks & 14.1 & $85 \%$ & $31-33$ \\
\hline & Containers & Annual collection & $89 \%$ & 2,34 \\
\hline & Other products & 12.1 & $50 \%$ & 15,29 \\
\hline \multirow{6}{*}{ 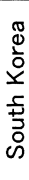 } & Buildings & 17 & $79 \%$ & 35 \\
\hline & Infrastructure & 50 & $39 \%$ & \\
\hline & Machinery & 12.1 & $89 \%$ & \\
\hline & Automobiles & 12.8 & $94 \%$ & \\
\hline & Containers & 3 & $98 \%$ & \\
\hline & Other products & 12.1 & $59 \%$ & \\
\hline \multirow{5}{*}{$\frac{\sqrt[c]{\pi}}{\stackrel{\frac{\pi}{\pi}}{\mathscr{N}}}$} & Construstion & 30 & $37 \%$ & 35 \\
\hline & Machinery & 5 & $67 \%$ & \\
\hline & Automobiles & 16.4 & $72 \%$ & \\
\hline & Containers & 3 & $11 \%$ & 38 \\
\hline & Other products & 5 & $37 \%$ & \\
\hline
\end{tabular}
Japan, South Korea and Taiwan. distribution was applied as the distribution function. The recovery rate of obsolete scraps from "machinery" was obtained from a previous study by Kakudate et al. ${ }^{25)}$ The recovery rates of obsolete scraps from end-of-life vehicles, i.e. "passenger cars" and "trucks and buses", were obtained for 1990 to $2001^{32)}$ and for 2002 to $2004 .^{33)}$ The recovery rates of obsolete scraps from discards of "containers" were obtained from a steel can recycling website. ${ }^{34)}$ The recovery rates of obsolete scraps from end-of-life "other products" were assumed to be the same as those for "machinery" following the same reasoning described above for the lifetime distribution. The obtained recovery rates for obsolete scraps from end-of-life "buildings" and "machinery" were 70$80 \%$ and $30-40 \%$, respectively, based on an interview survey. ${ }^{6}$

Obsolete scrap recovery by end use for each prior year was estimated from the steel input by end use using the PBM as described above. The results for the years 1991 to 2004, shown in Fig. 1(a), are compared with the amounts of obsolete scrap recovery estimated in Sec. 2.2. As shown in the figure, the data corresponded when the recovery rates

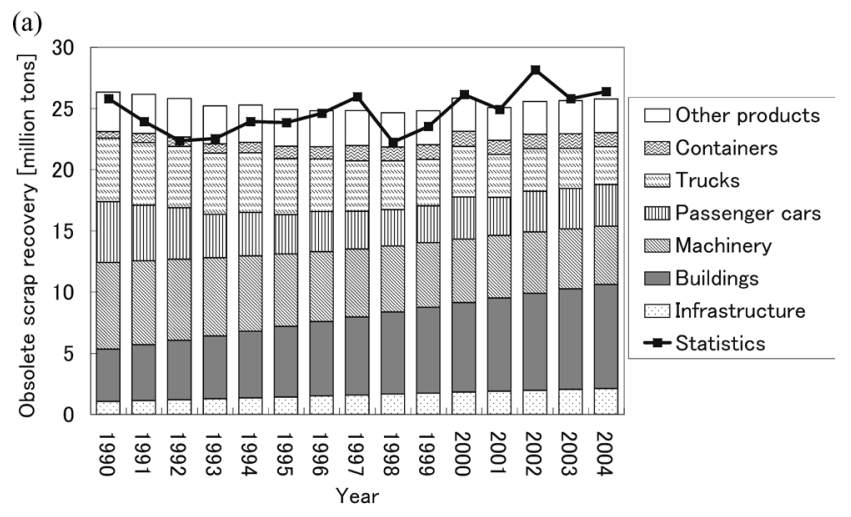

(b)
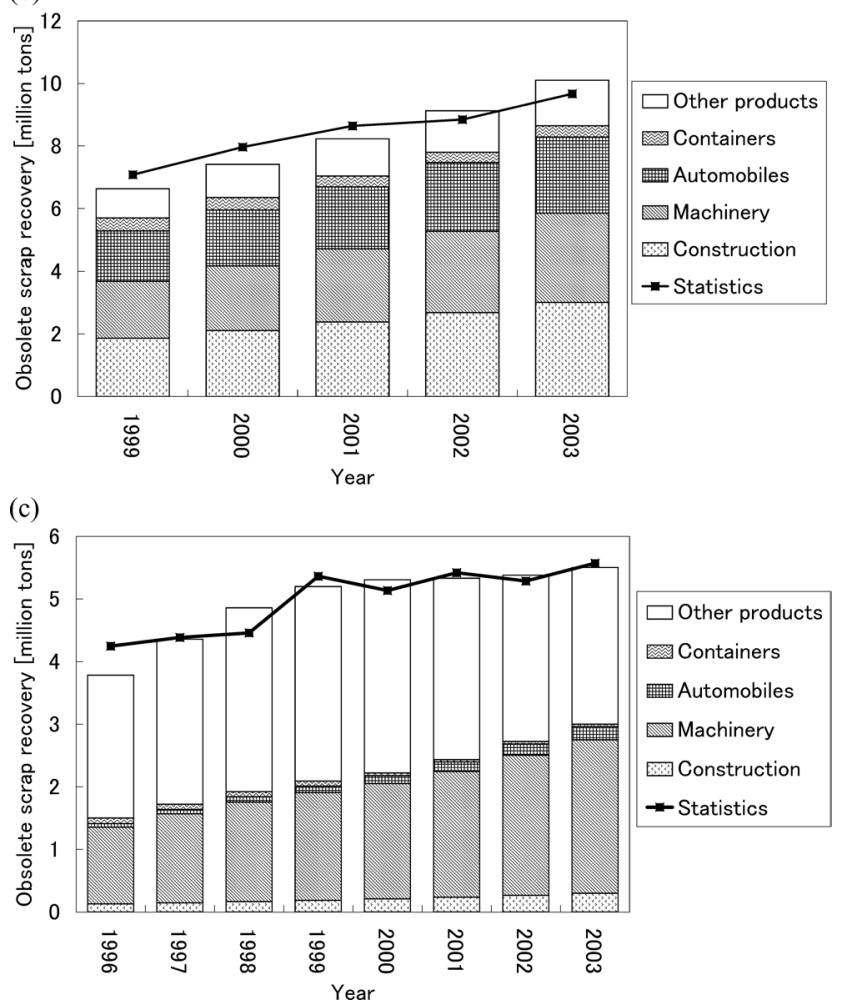

Fig. 1. Statistics and estimation of obsolete scrap recovery in (a) Japan, (b) South Korea, (c) Taiwan. 
for obsolete scraps were $70 \%$ and $30 \%$ for "buildings" and "infrastructure", respectively, and $50 \%$ for "other products".

The parameters used for South Korea were set in the following manner. The average lifespan of steel for "infrastructure" was assumed to be 50 years, which is the legal useful life in Japan. ${ }^{35)}$ In the same way, the average lifespan of steel for "containers" was assumed to be 3 years. The average lifespan of steel for "machinery" was assumed to be 12.1 years, which is the same as in Japan.

The average lifespan of steel for "automobiles" in Korea was estimated in the following manner. The number of automobiles produced, imported, and exported was estimated based on statistics, ${ }^{18)}$ as described in Sec. 2.1. Changes in number of owned automobiles were obtained from Ministry of Construction \& Transportation, Korea. ${ }^{36)}$ The number of discarded automobiles each year could be derived from the change in the number of owned automobiles reported for the previous year and the number of newly registered automobiles (production+imports-exports) in the year. The average lifespan was determined as shown in Table 1. The change in lifespan was assumed to be the same as that in Japan.

The average lifespan of steel for "buildings" was estimated in the following manner. The housing space per capita and the area covered by new housing construction were obtained from the Ministry of Construction \& Transportation, Korea. ${ }^{37)}$ The area of housing could be obtained by multiplying the housing space per capita by population. The area demolished in a given year could be derived from the change in the area of housing reported for the previous year and the area of new housing construction in a given year. The average lifespan was determined as shown in Table 1. To apply the Weibull distribution, a shape parameter was needed in addition to the average lifespan. However, the shape parameter could not be obtained. Therefore, the shape parameters for each end use were assumed to be 3.5 because the shape parameters in Japan were between 3 and 4. The lifetime distribution of steel for "other products" was assumed to be the same as that of "machinery," as was decided for Japan. The recovery rates of obsolete scraps were determined as shown in Table 1 under the condition that the residual sum of squares of the estimation based on statistics and the estimation calculated by the PBM was minimized during the preceding 5 years.

The PBM was applied to steel input by end use, and obsolete scrap recovery by end use was estimated. As shown in Table 1, the lifetime distribution of "buildings" and "infrastructure" could be estimated separately. The ratio of steel input of "buildings" to "infrastructure" has been 2 to 1 in Japan in recent years. Therefore, the input for "construction" was divided into "buildings" and "infrastructure" based on this ratio. The results for the years 1999 to 2003 , shown in Fig. 1(b), were compared with the amount of obsolete scrap recovery estimated in Sec. 2.2.

Finally, the parameters used for Taiwan were set in the following manner. Obsolete scrap recovery had increased rapidly in Taiwan in the past. However, the amount of recovery has been stable in recent years. The recovery rate of obsolete scraps does not decline when demand for scraps is strong. The average lifespan of steel for "machinery" was assumed to be 5 years. The average lifespan of steel for "construction" was assumed to be 30 years, which is the legal useful life in Japan. ${ }^{35)}$ In the same way, the average lifespan of steel for "containers" was assumed to be 3 years.

The average lifespan of steel for "automobiles" in Taiwan was estimated in the following manner. The numbers of cars produced, imported, and exported were estimated based on statistics, ${ }^{19-21)}$ as described in Sec. 2.1. Changes in the number of owned automobiles were obtained from literature. ${ }^{20,21)}$ The number of discarded automobiles in a given year could be derived from the change in the number of owned automobiles reported for the previous year and the number of newly registered automobiles (production + imports-exports) in a given year. The average lifespan was determined as shown in Table 1. The change in lifespan was assumed to be the same as that for Japan. The shape parameter was assumed to be 3.5, reflecting the values in Japan, which ranged between 3 and 4 . The recovery rate of steel for "containers" was set at $11 \%$ based on the previous study by Lee et al. ${ }^{38)}$ The lifetime distribution of steel for "other products" was assumed to be the same as that of "machinery", as was the case for Japan. The recovery rates of obsolete scraps were determined as shown in Table 1, with the exception of "containers", under the condition that the residual sum of squares for the estimation based on statistics and the estimation calculated by the PBM was minimized during the preceding 5 years.

The PBM was applied to the input by end use, and the amount of obsolete scrap recovery by end use was estimated. The results for the years 1996 to 2003, shown in Fig. 1(c), are compared with the amount of obsolete scrap recovery estimated in Sec. 2.2 .

The parameters used for China were set in the following manner to enable the application of the leaching model.

$$
\operatorname{Stock}(t)=\operatorname{Stock}\left(t_{0}-1\right)+\sum_{x=t_{0}}^{t}(I(x)-O(x)) .
$$

where $\operatorname{Stock}(t)$ : steel stock in year $t, t_{0}$ : the start year for steel stock, $I(x)$ : steel input in year $x$, and $O(x)$ : obsolete scrap recovery in year $x$.

Steel stock was estimated using Eq. (4) until 2004, at which time $t_{0}$ had to be set to a year when $\operatorname{Stock}\left(t_{0}-1\right)$ could be regarded as 0 . In the current study, $t_{0}$ was set to 1926 when the increase in steel stock, which was estimated using an exponential approximation described later, was less than 1000 t. Steel input from 1949 to 2004, which was estimated in Sec. 2.1, was used as $I(x)$.

Obsolete scrap recovery $O(x)$ was estimated in the following manner. Crude steel production in China from 1949 to 2004 was obtained. ${ }^{9)}$ Total scrap recovery from 1949 to 2004 was obtained by assuming that the specific scrap consumption of steel production in years prior to 1983 was the same as that in 1983. Furthermore, in-house scrap generation from 1949 to 2004 was obtained by assuming that the generation rate of in-house scraps in years prior to 1993 was the same as that in 1993. Imports and exports of scraps in years prior to 1984 could be considered negligible compared to total scrap recovery and were regarded as 0. From these estimations, obsolete scrap recovery from 1949 to 
2004 was estimated using the method described in Sec. 2.2.

The increase in steel stock was derived by subtracting scrap recovery from steel input. The increase in steel stock from 1926 to 1948 was estimated using an exponential approximation of the data from 1949 to 1960. Steel stock from 1926 to 2004 was estimated using this increase in steel stock. China has announced its five-year plan, which estimates that crude steel production and steel input in 2010 will reach 440 million tons and 420 million tons, respectively. ${ }^{1)}$ Therefore, steel input from 2005 to 2010 was determined based on this estimate assuming that the rate of change will remain constant over the period. By using Eq. (3), steel stock from 2005 to 2010 was estimated. Here, the generation rate of obsolete scraps $C_{\text {Leaching }}$ was assumed to remain constant at the 2004 level (0.00667).

\section{Results and Discussion}

\subsection{Future Forecast of Steel Input}

In the present study, three methods were used to forecast future steel input. The first assumed that steel input in the future will remain constant at the present level, which was applied in the authors' previous study. ${ }^{2)}$ Future steel input was assumed to be the same as that for the latest available data.

The second method forecasted future steel stock by performing the logistic curve regression analyses shown in Eq. $(5){ }^{39)}$

$$
S_{t}=\frac{S_{\max }}{1+e^{\beta_{0}-\beta t}}
$$

where $S_{t}$ : steel stock $t$ years after steel stock initiation, $S_{\max }$ : steel stock convergence, $\beta_{0}$ and $\beta$ : parameters, and $t$ : the number of years since steel stock initiation. In the present study, $S_{\max }$ was set at $14 \mathrm{t} /$ capita because the steel stock per capita in the United States has shown a point of saturation at this value recently. ${ }^{40)}$ The change in steel stock is equal to the obsolete scrap recovery subtracted from the input as shown in Eq. (6), making the forecasting of future input possible.

$$
\frac{d S(t)}{d t}=I(t)-O(t)
$$

where $d S(t) / d t$ : change in steel stock in year $t, I(t)$ : steel input in year $t$, and $O(t)$ : obsolete scrap recovery in year $t$.

Different approaches were used for China than for the other three countries, Japan, South Korea and Taiwan. For China, future steel stock was forecast using the logistic curve regression as describe in the first step. Next, the leaching model was applied to forecast future obsolete scrap recovery. Finally, future steel input was forecast by adding the obsolete scrap recovery to the change in steel stock. For Japan, South Korea and Taiwan, future steel stock was forecast using the logistic curve regression in the same manner as for China. However, the PBM was applied to the steel input for the most recent available data to calculate the obsolete scrap recovery in the following year. Then, steel input for the same year was obtained by adding the obsolete scraps recovery to the change in steel stock for the year (see Eq. (6)). Then, the PBM was applied to the steel input for the forecast year, and obsolete scrap recovery in the following year was calculated. The same procedure was repeated, and future steel input and obsolete scrap recovery were forecast. The parameters used in the logistic regressions are shown in Table 2.

The third method forecasted steel input by end use by applying regression equations that adopt gross domestic product (GDP) and population as explaining variables. Future steel input could then be forecast by setting the future changes in GDP and population. Regression analyses were conducted for each end use. The equations are shown in Table 3. Future forecasts of $\mathrm{GDP}^{41,42)}$ and population ${ }^{23,43-45)}$ were substituted into the equations and future steel input by end use was forecast.

Table 2. Parameters for logistic curves.

\begin{tabular}{|c|c|c|}
\hline & $\beta_{0}$ & $\beta$ \\
\hline Japan & 6.878 & 0.06907 \\
\hline China & 8.376 & 0.08422 \\
\hline South Korea & 10.11 & 0.1258 \\
\hline Taiwan & 11.87 & 0.1771 \\
\hline
\end{tabular}

\begin{tabular}{|c|c|c|c|}
\hline & & Regression equation & $\mathrm{R}^{2}$ \\
\hline \multirow{7}{*}{ 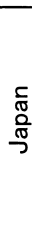 } & Buildings & $\mathrm{S} /$ capita $=4000 /(1+\exp (3.1-0.011 \mathrm{GDP} /$ capita $))$ & 0.98 \\
\hline & Infrastructure & S/capita $=3000 /(1+\exp (2.4-0.008 \mathrm{GDP} /$ capita $))$ & 0.98 \\
\hline & Machinery & Input $/$ capita $=4.85 * 10^{2} \Delta \mathrm{GDP} /$ capita +51.0 & 0.37 \\
\hline & Passenger cars & Use $/$ capita $=600 /(1+\exp (3-0.009 \mathrm{GDP} /$ capita $))$ & 0.96 \\
\hline & Truckes & $\Delta$ Use $/$ capita $=0.888 \Delta \mathrm{GDP} /$ capita -0.00786 & 0.32 \\
\hline & Containers & Input $/$ capita $=0.0458 \mathrm{GDP} /$ capita -7.17 & 0.78 \\
\hline & Other products & Input $=0.800$ Input $M+1.68 * 10^{5}$ & 0.47 \\
\hline \multirow{5}{*}{$\stackrel{\frac{\pi}{2}}{\frac{\mathscr{C}}{0}}$} & Construction & Input $=-3765+1226 \mathrm{GDP} /$ capita & 0.86 \\
\hline & Machinery & Input $=6626+235 \mathrm{GDP} /$ capita & 0.27 \\
\hline & Automobiles & Input $=-721+135 \mathrm{GDP} /$ capita & 0.73 \\
\hline & Containers & Input $=340+16 \mathrm{GDP} /$ capita & 0.51 \\
\hline & Other products & Input $=-10053+6550 \mathrm{GDP} /$ capita & 0.82 \\
\hline \multirow{5}{*}{ 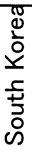 } & Construction & Input $=-2602+1.71 \mathrm{GDP} /$ capita & 0.92 \\
\hline & Machinery & Input $=-368+0.48 \mathrm{GDP} /$ capita & 0.79 \\
\hline & Automobiles & Input $=-136+0.405 \mathrm{GDP} /$ capita & 0.75 \\
\hline & Containers & Input $=-59+0.0452 \mathrm{GDP} /$ capita & 0.91 \\
\hline & Other products & Input $=-224+0.262 \mathrm{GDP} /$ capita & 0.83 \\
\hline \multirow{5}{*}{$\frac{\sum^{\frac{\pi}{\sigma}}}{\frac{\pi}{\sigma}}$} & Construction & Input $=-1182+0.255 \mathrm{GDP} /$ capita & 0.97 \\
\hline & Machinery & Input $=-578+0.115 \mathrm{GDP} /$ capita & 0.86 \\
\hline & Automobiles & Input $=-173+0.0298 \mathrm{GDP} /$ capita & 0.86 \\
\hline & Containers & Input $=-30+0.0181 \mathrm{GDP} /$ capita & 0.7 \\
\hline & Other products & Input $=-389+0.153 \mathrm{GDP} /$ capita & 0.85 \\
\hline
\end{tabular}

Table 3. Regression equations for each end use in Japan, South Korea, Taiwan, and China. 
(a)

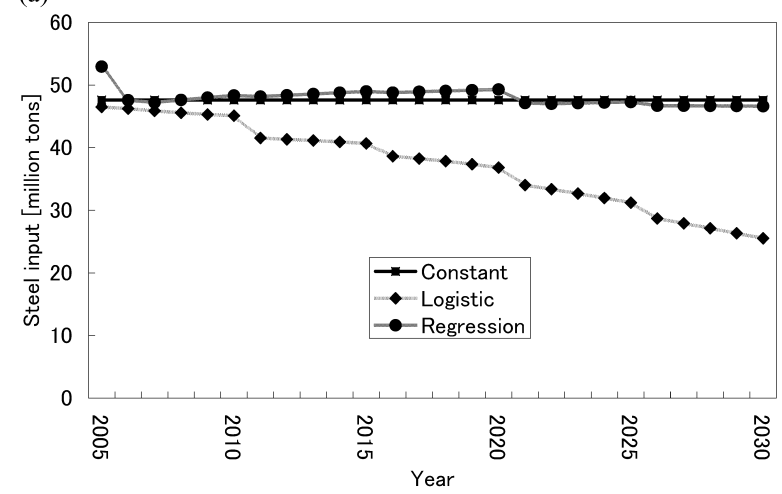

(b)

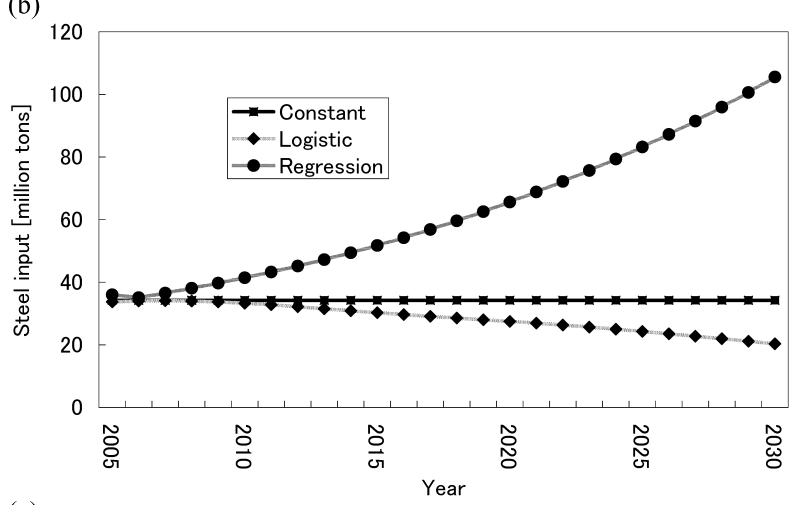

(c)

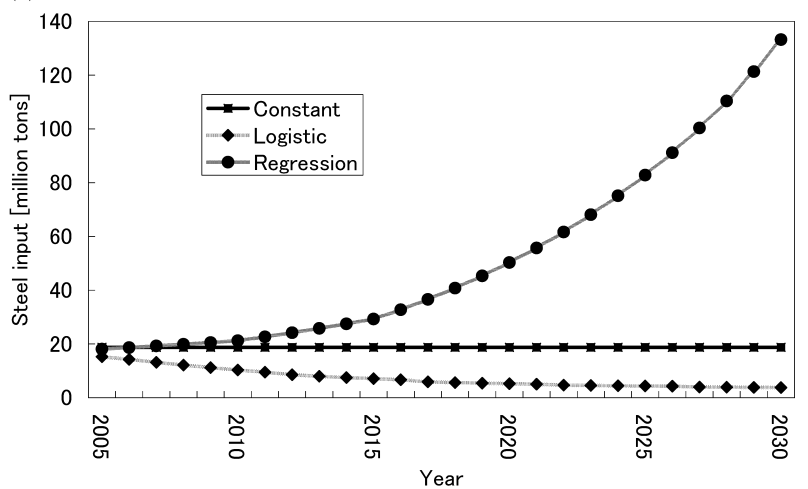

(d)

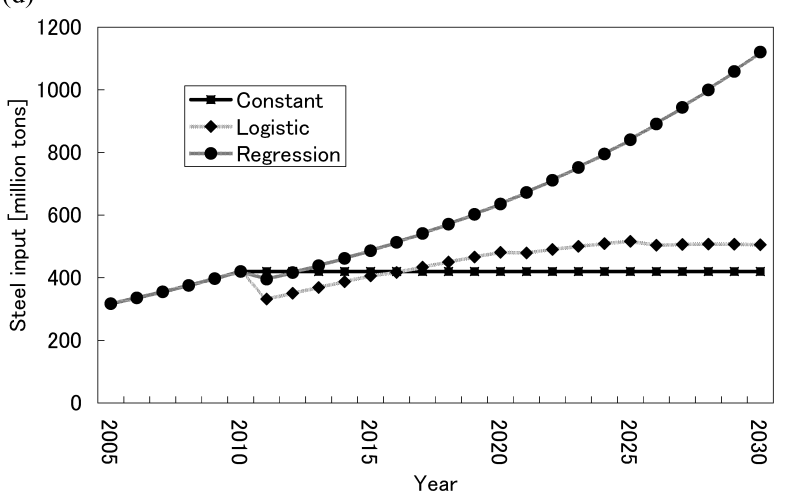

Fig. 2. Amount of future steel input forecasted by three methods in (a) Japan, (b) South Korea, (c) Taiwan, (d) China.

The results of future steel input forecasts using the three methods are shown in Figs. 2(a)-2(d).

The logistic curve method forecasted that steel input in China would gradually increase in the future. In contrast, for Japan, South Korea and Taiwan, the logistic curve method forecasted that steel input would gradually decrease. The two sets of results occurred because the present steel stock per capita in Japan, China, South Korea and Tai- wan are $10 \mathrm{t}, 2.0 \mathrm{t}, 8.0 \mathrm{t}$, and $12 \mathrm{t}$, respectively, and the steel stock per capita convergence was set at $14 \mathrm{t}$. Therefore, the change in steel stock per capita increased until steel stock per capita reaches $7 \mathrm{t}$, after which in the change in steel stock per capita began to decrease. Using the regression equation method, steel input in Japan was forecast to remain at the present level. On the other hand, steel input in China, South Korea and Taiwan was forecast to greatly increase. However, considering the present numbers of existing blast furnaces in each country this forecast is not realistic.

Regression analysis has often been applied in previous studies of material flow analysis to forecast the future. ${ }^{3-5)}$ However, the present study showed the difficulty of using regression analysis to forecast the future using past trends in countries such as China, South Korea and Taiwan, where steel input has increased rapidly only in recent years.

\subsection{Forecast of Future Obsolete Scrap Recovery}

Future steel input, which was obtained in Sec. 3.1, was substituted into the obsolete scrap recovery estimation model developed in Sec. 2.3 to estimate future obsolete scrap recovery. The results are shown in Figs. 3(a)-3(d). Here, obsolete scrap recovery is shown by end use for the logistic curve method only, for Japan, South Korea and Taiwan, where the PBM was applied.

As shown in the figure, the results differed greatly depending on the steel input estimation method. Therefore, it is necessary to further refine the steel input forecasting method. Correlation between steel input and GDP has been reported previously. ${ }^{3,4)}$ Therefore, the changes in future obsolete scrap recovery, forecasted using the logistic curve method, will be described in detail below.

Obsolete scrap recovery in Japan was forecast to increase gradually, exceeding 33 million tons in 2020, and then decreasing to approximately 31 million tons by 2030 . Obsolete scrap recovery in South Korea was forecast to increase gradually, reaching approximately 21 million tons in 2023, and then decreasing to approximately 20 million tons in 2030. The logistic curve method, which was used to forecast steel input, predicted a decrease in 2005 in Japan and in 2008 in South Korea. However, the difference between the forecasts of obsolete scrap recovery using the logistic curve method and using the constant input method was small because the decrease in steel input affected obsolete scrap recovery after a certain period of time, due to the lifetime distributions. Obsolete scrap recovery from "passenger cars" and "buildings" were predicted to increase in Japan for two reasons. First, steel input for "passenger cars" has increased in recent years although the total steel input has remained almost constant. Secondly, steel used for "buildings" has a considerably long average lifespan. Similarly, obsolete scrap recovery from "buildings" was forecast to increase in South Korea and this increase would account for most of the increase in the total obsolete scrap recovery.

Obsolete scrap recovery in Taiwan was forecast to decrease gradually, and fall to approximately 3 million tons in 2030. Obsolete scrap recovery from "machinery" and "other products" would decrease in particular, while obsolete scrap recovery from "construction" and "automobiles" would increase. Steel input was forecast to decrease after 
(a)

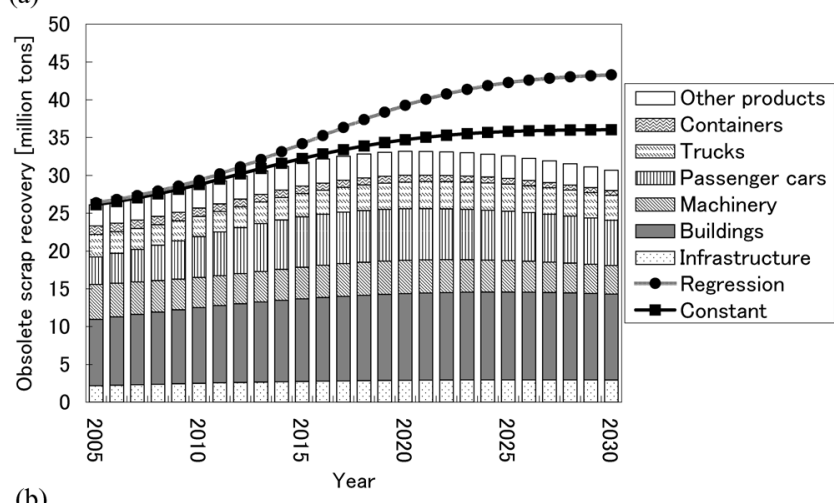

(b)

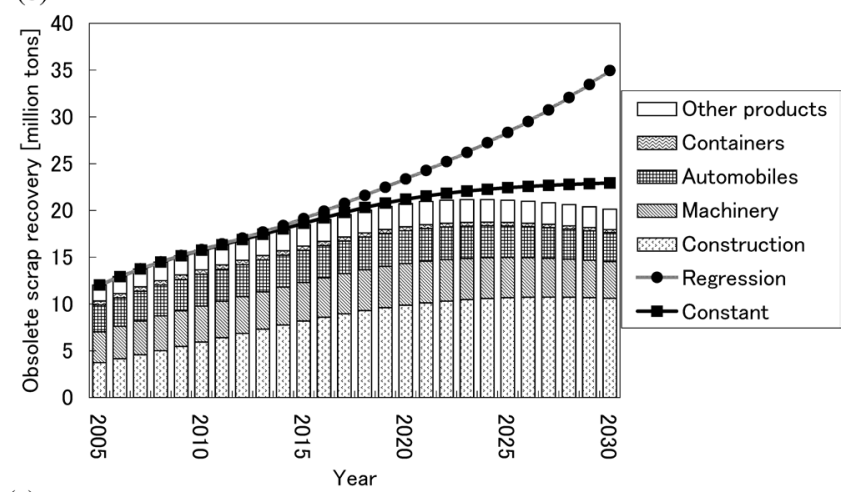

(c)

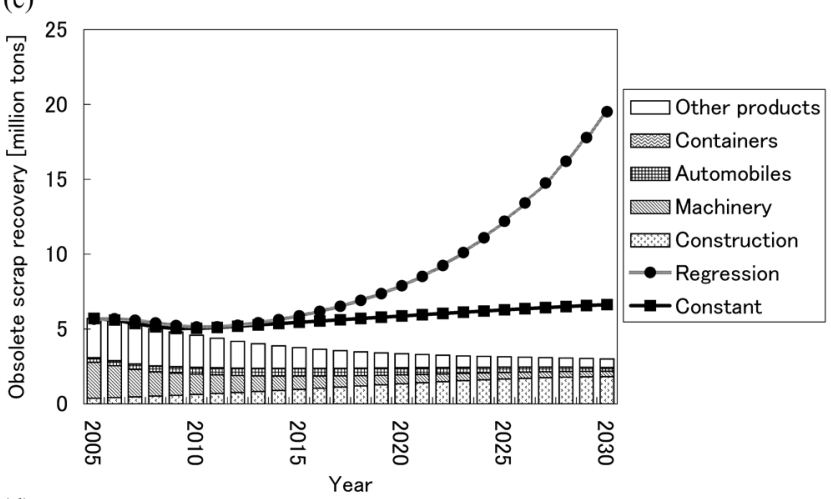

(d)

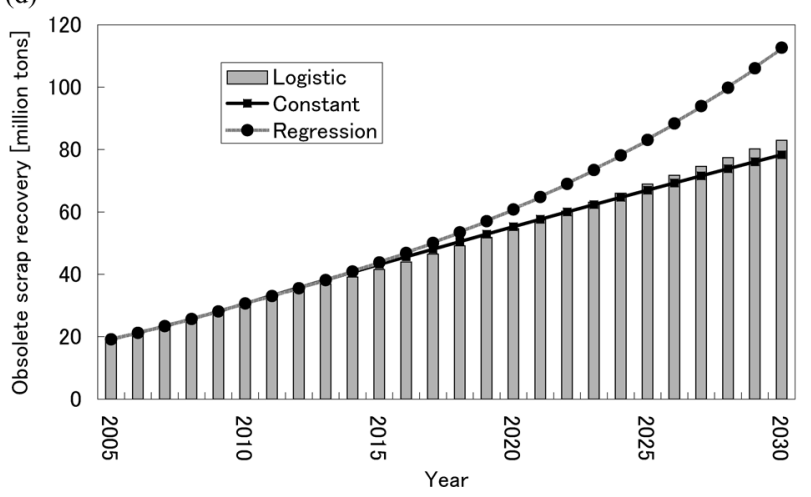

Fig. 3. Amount of future obsolete scrap recovery estimated by three methods in (a) Japan, (b) South Korea, (c) Taiwan, (d) China.

2004, as shown in Fig. 3(c). The decreasing trend in obsolete scrap recovery from "construction", which has a long average lifespan, was evident after a certain period of time, while the trend for "machinery", which has a short average lifetime, could be seen in an earlier stage.

Obsolete scrap recovery in China was forecast to exceed 80 million tons in 2030. Changes in steel stock directly af- fected changes in obsolete scrap recovery under the leaching model, which was applied for China. The difference in obsolete scrap recovery using the constant steel input method and the logistic curve method under the leaching model was small.

In addition, the logistic curve method forecasted that obsolete scraps recovery would exceed the demand for scraps in 2021 in China, in 2010 in South Korea, and in 2006 in Taiwan.

\section{Conclusions}

In the present study, a dynamic material flow model was developed using a combined PBM and leaching model. Obsolete scrap recovery was estimated by end use, applying the PBM for Japan, South Korea and Taiwan, and the leaching model for China.

Moreover, three methods were proposed to forecast future steel input and future obsolete scrap recovery. The forecasted obsolete scrap recovery values differed significantly between the methods. As a result, further refinement of the steel input forecast method is needed. The logistic curve method forecasted that obsolete scrap recovery in 2030 would be 29 million tons in Japan, 83 million tons in China, 20 million tons in South Korea, and 3.7 million tons in Taiwan.

\section{Acknowledgements}

The authors are grateful to the Ministry of Education, Culture, Sports, Science and Technology, which subsidized the current study.

\section{REFERENCES}

1) The Japan Ferrous Raw Materials Association: Current Status and Perspective of Supply and Demand of Ferrous Raw Materials (in Japanese), Tokyo, (2006), 25, 26, 33, 42, 110, 111, 124.

2) I. Daigo, D. Fujimaki, Y. Matsuno and Y. Adachi: Tetsu-to-Hagané, 91 (2005), 171.

3) D. P. van Vuuren, B. J. Strengers and H. J. M. De Vries: Resour. Policy, 25 (1999), 239.

4) P. Crompton: Resour. Policy, 26 (2000), 103.

5) A. Elshkaki, E. Van der Voet, M. Van Holderbeke and V. Timmermans: Resour. Conserv. Recycl., 42 (2004), 133.

6) Japan Technical Information Service: private communication, (2006).

7) The Japan Ferrous Raw Materials Association: Quarterly Ferrous Raw Material Statistics, Tokyo, 24, (2005), 19.

8) Ministry of International Trade and Industry: Yearbook of Iron and Steel Statistics, Tokyo, (1954-1970).

9) The Japan Iron and Steel Federation: Handbook for Iron and Steel Statistics, Tokyo, (2005), 74, 75, 84, 85.

10) The Japan Iron \& Steel Exporters' Association: Handbook for Iron and Steel in Major Countries (in Japanese), 1st-8th Tokyo, (1984-2001).

11) China Machine Press: China Machinery Industry Yearbook 2004, Beijing, (2004), 19, 67, 557.

12) Publishing House of Electronics Industry: China Electronics Industry Yearbook 1999, Beijing, (1999), 24.

13) Publishing House of Electronics Industry: China Electronics Industry Yearbook 2004, Beijing, (2004), 17, 21, 22.

14) China Machine Press: China Machinery Industry Yearbook 2003, Beijing, (2003), 530.

15) The Japan Iron and Steel Federation: Iron and Steel Sales Statistics by End-uses and Regions (in Japanese), Tokyo, (1991), 135.

16) International Iron and Steel Institute (IISI): Steel Statistical Yearbook, Brussels, (1983-2004). 
17) The Japan Ferrous Raw Materials Association: Year Book of Ferrous Raw Material Statistic 2005, Tokyo, (2006), 52.

18) Japan Automobile Manufacturers Association: World Motor Vehicle Statistics 2006, (2006), 5, 123, 145.

19) Taiwan Transportation Vehicle Manufacturers Association, Website: http://www.ttvma.org/information.php (Accessed date: Nov. 15, 2006)

20) Interchange Association Japan, Website: https://www.jptwbiz-j.jp/ bizinfo_j/tmk_j/pdf/topics/tp030219_j.pdf (Accessed date: Nov. 15, 2006)

21) N. Junpei: Doshisha Univ. Worldwide Bus. Rev., 3 (2002), 20.

22) Nikkyo Tsushin: Taiwan-keizai-soran, Taipei, (2005), 328.

23) Taiwan-mondai-kenkyusho, Taiwan-soran, Tokyo, (2001), 24, 412.

24) W. Tamaki, Y. Igarashi, D. Fujimaki, S. Hayashi, Y. Tomota, Y. Matsuno and T. Nagasaka: Tetsu-to-Hagané, 92 (2006), 334.

25) K. Kakudate, Y. Adachi and T. Suzuki: Tetsu-to-Hagané, 86 (2000), 837.

26) E. van der Voet, R. Kleijn, R. Huele, M. Ishikawa, E. Verkuijlen: Ecol. Econ., 41 (2002), 223.

27) Y. Komatsu, Y. Kato, T. Yoshida and T. Yashiro: J. Archit. Plan. Environ. Eng., No. 439, (1992), Sep.

28) Ministry of Land Infrastructure and Transport: White Paper on Land Infrastructure and Transport 2006, Gyosei, Tokyo, (2006).

29) A. Toi and J. Sato: Energy Resour, 18 (1997), 271.

30) Y. Adachi, I. Daigo, H. Yamada and Y. Matsuno: Dev. Eng., 11 (2005), 19

31) D. Fujimaki: Master Thesis, University of Tokyo, (2006).

32) Japan Automobile Research Institute: Survey Report on Research and Developments in High-technology Intensive Industries (in Japanese), Tokyo, (2003), 13.
33) Trade Statistics of the Ministry of Finance Japan, Website: http://www.customs.go.jp/toukei/info/index.htm (Accessed date: Dec. 3, 2006)

34) Japan Steel Can Recycling Association, Website: http://www.steelcan.jp/ (Accessed date: Dec. 1, 2006)

35) H. Takagishi: Useful Life Table for Depreciable Assets and How to Use (in Japanese), Horei, Tokyo, (2003), 28.

36) Ministry of Construction \& Transportation, Korea, Website: http://minwon.moct.go.kr/Civil/Search/EngListMain.jsp?QU = \&FD $=0 \& \mathrm{CCH}=1 \& \mathrm{DT} 1=\& \mathrm{DT} 2=\& \mathrm{SH}=0 \& \mathrm{PART}=\& \mathrm{LC}=10 \& \mathrm{CT}=3$ $\& F D 2=\& \& P G=3$ (Accessed date: Dec. 5, 2006)

37) Ministry of Construction \& Transportation, Korea, Website: http://www.moct.go.kr/EngHome/DataCenter/Statistic/Statistic01.ht $\mathrm{m}$ ?oneDep $=4 \&$ twoDep $=42$ (Accessed date: Dec. 5, 2006)

38) Y.-M. Lee, A. M.-J. Cheng and C.-Su: Eco Balance Overview, (2006), 385

39) A. Toi and J. Sato: Tetsu-to-Hagané, 84 (1998), 534.

40) The Iron and Steel Institute of Japan, Proc. of Symp. on Development of Materials Strategy Model for Resource and Environment, Tokyo, (2007), 18.

41) Japan Center for Economic Research: Long-term Forecast of Global Economy and Population 2006-2050, (2007), 145.

42) Kyoto University Pacific Rim Databases, Website: http://www. econ.kyoto-u.ac.jp/pacific/ (Accessed date: Dec. 20, 2006)

43) Statistics Bureau, Ministry of Internal Affairs and Communications: Japan in Figures, Tokyo, (2006).

44) United Nations, Website: http://esa.un.org/unpp/ (Accessed date: Dec. 10, 2006)

45) Korean Statistical Information Service, Website: http://kosis.nso.go. kr/Magazine/NEW/PJ/PJ0104.xls (Accessed date: Dec. 10, 2006) 